\title{
Correlation Between MERI and Hearing After Tympanoplasty
}

\author{
Sharma $A^{1}$, Saxena $R K^{2}$, Verma $L R^{3}$, Bhandari $S^{4}$
}

\begin{abstract}
Background: Chronic otitis media is otological challenge in the developing countries it is particularly single most common cause of hearing impairement. Objective: The objective of this study was to observe the impact of prognostic factor middle ear risk index on hearing of patients undergoing tympanoplasty for chronic otitis media. Methods: This was a prospective analytical study conducted in 50 patients planned for tympanoplasty for chronic otitis media and evaluation done by MERI (Middle Ear Risk Index) and pure tone audiometry. Results: This study shows that most of the patients had mild MERI (64\%), followed by severe MERI (20\%) and then moderate MERI (16\%). The mean preoperative PTA average was $44.34 \mathrm{~dB}$ (SD $8.01 \mathrm{~dB}$ ) for patient with mild MERI, $44.75 \mathrm{~dB}$ (SD 5.87 $\mathrm{dB}$ ) for patient with moderate MERI, and $54.9 \mathrm{~dB}$ (SD $14.05 \mathrm{~dB}$ ) for patient with severe MERI and the mean preoperative A-B gap was $37.36 \mathrm{~dB}$ (SD $5.73 \mathrm{~dB}$ ). Post operatively for mild MERI mean hearing gain is $12-14 \mathrm{~dB}$, for moderate MERI mean hearing gain is $10-13 \mathrm{~dB}$ and for severe MERI mean hearing gain is $10-13 \mathrm{~dB}$ and post operative mean A-B gap was improved by $10-11 \mathrm{~dB}$. There is a statistically significant hearing improvement in A-B gap with different types of MERI. Conclusion: MERI scoring is useful for predicating the outcome of hearing after tympanoplasty.
\end{abstract}

Key words: Chronic otitis media, middle ear risk index, tympanoplasty

\section{INTRODUCTION}

Chronic otitis media (COM) is otological challenge in the developing countries it is a persistent disease causing severe destruction of middle ear with irreversible sequale ${ }^{1}$. In 1965, the American Academy of Ophthalmology and Otolaryngology Subcommittee on Conservation of Hearing set forth a standard classification for surgery of chronic middle ear infection and defined tympanoplasty as a procedure to eradicate disease in middle ear and to reconstruct the hearing mechanism². Kartush has introduced the MERI for the prognosis of tympanoplasty. Becvarovski and Kartush revised and updated middle ear risk index in 2001 which generates a numeric indicator of the severity of the middle ear disease and is used to predict the outcome of tympanoplasty.

MERI combines the known preoperative and intraoperative risk factors for tympanoplasty prognosis into a numeric value. Kartush modified the Austin classification and presented the middle ear risk index (MERI) to define those basic data and to classify cases in different prognostic categories. The factors they monitored included otorrhea, perforation of the eardrum, cholesteatoma, ossicular status, middle ear

\footnotetext{
1. Dr. Anshu Sharma

2. Prof. R. K. Saxena

3. Dr. Lok Ram Verma

4. Dr. Shama Bhandari
}

Address for correspondence:

Dr. Anshu Sharma

Department of E.N.T.

Nepalgunj Medical College Teaching Hospital

Kohalpur, Banke, Nepal

Email: anshusa.regmi@gmail.com granulations or effusions, previous surgery and smoking, and they assigned a risk value to each of these factors. It also allows meaningful study comparisons by delineating essential data and stratifying cases within various prognostic categories. There are various reports discussing prognostic factors in tympano-mastoid surgery and their impact on hearing results ${ }^{3}$. Black introduced the system of Surgical, Prosthetic, Infection, Tissues and Eustachian tube function (SPITE), as prognostic indicators for tympanoplasty ${ }^{4}$.

Tympanoplasty is a surgical procedure performed to eradicate infection and restore the function of the middle ear. Wullstein introduced a classification for tympanoplasty that is based on two things: (1) the remaining structures of the middle ear after all pathology has been eradicated, and (2) how sound is transferred to the oval window while the round window is being protected ${ }^{5}$.

The purpose of this study is to verify the correlations of MERI with result of tympanoplasty and post operative hearing gain in patients classified according to MERI.

\section{MATERIAL AND METHODS}

This is a Prospective analytical study conducted from July 2014 to April 2015 in the department of otorhinolaryngology, Nepalgunj Medical College Teaching Hospital, Kohalpur in 50 patients undergoing tympanoplasty. Inclusion criteria were patients of either sex, age between 7-50 years, patients with COM (mucosal and squamous). Exclusion criteria were patients age $<7$ years and $>50$ years, COM with complications, patients with any comorbid medical conditions and unwilling patients.

All patients were admitted to the hospital at least a day before surgery and went a through history taking, ENT examination, 
Sharma et al.: Correlation Between MERI and Hearing After Tympanoplasty

\begin{tabular}{|c|c|c|c|c|c|c|c|}
\hline \multicolumn{2}{|c|}{ Otorrhea } & Perforation & Cholesteatoma & $\begin{array}{c}\text { Ossicle } \\
\text { status }\end{array}$ & ME Pathology & $\begin{array}{c}\text { Previous } \\
\text { surgery }\end{array}$ & Smoker \\
\hline Dry & None & None & M+l+S+ & No & None & No & 0 \\
\hline Occasional Wet & Present & Present & M+S+ & & Staged & & 1 \\
\hline Persistent Wet & & & M+S- & Yes & Revision & Yes & 2 \\
\hline Wet Cleft Palate & & & M-S+ & & & & 3 \\
\hline & & & M-S- & & & & 4 \\
\hline & & & Ossicle head fix & & & & 2 \\
\hline
\end{tabular}

Total MERI Index: MERI 0- Normal, MERI 1-3 mild diseases, MERI 4-6 moderate disease, MERI 7-12 severe disease

Table I: Middle Ear Risk Index

along with MERI and audiological examination pre and post operative using ALPS AD2100 (calibrated according to ISO 1964 specifications) air and bone conduction were measured for 250, 500, 1000, 2000, 4000 Hertz and the resulting level was expressed in $\mathrm{dB}$ hearing loss and degree of hearing loss is calculated according to WHO criteria. Masked PTA was done if the air bone gap (A-B) was more than $40 \mathrm{~dB}$.

After thorough evaluation and preoperative preparation patients were shifted to operation theatre for tympanoplasty ossicular status was assessed at the time of operation. According to the MERI carried out for 50 ears studied, assessment was done for suggested risk categories, number of ears that fall in each category and result of tympanoplasty.

STATISTICAL ANALYSIS: Significance level was assessed by calculating ' $p$ ' value using t-test and chi-square test, $p$-value less than 0.05 was considered significant.

\section{RESULT}

In the demographic profile the mean age of the patient was 22.66(SD 9.16) years with the minimum and maximum age of 7 and 50 years respectively. There was no significant difference among the genders of the study patient. After tympanoplasty patients were followed up for three months at $1^{\text {st }}, 2^{\text {nd }} \& 3^{\text {rd }}$ month. Patients were assessed for graft uptake, average hearing threshold and A-B gap.

\begin{tabular}{|c|c|c|}
\hline Symptoms & No. of cases & Percentage \\
\hline Ear Discharge & 48 & 96 \\
\hline Hearing Loss & 49 & 98 \\
\hline Otalgia & 4 & 8 \\
\hline Vertigo & 8 & 16 \\
\hline Tinnitus & 11 & 22 \\
\hline Headache & 0 & 0 \\
\hline
\end{tabular}

Table II: Distribution based on symptoms of patient

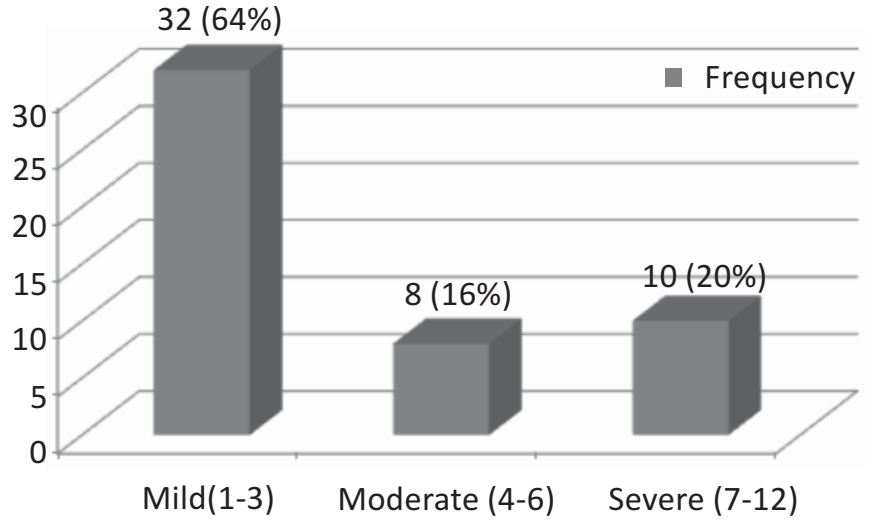

Figure 1: Distribution based on pre-operative MERI

\begin{tabular}{|c|c|}
\hline MERI & Mean PTA average (dB) \\
\hline Mild & $44.34 \pm 8.01$ \\
\hline Moderate & $44.75 \pm 5.87$ \\
\hline Severe & $54.9 \pm 14.05$ \\
\hline
\end{tabular}

Table III: MERI correlation with mean pre operative PTA average

100

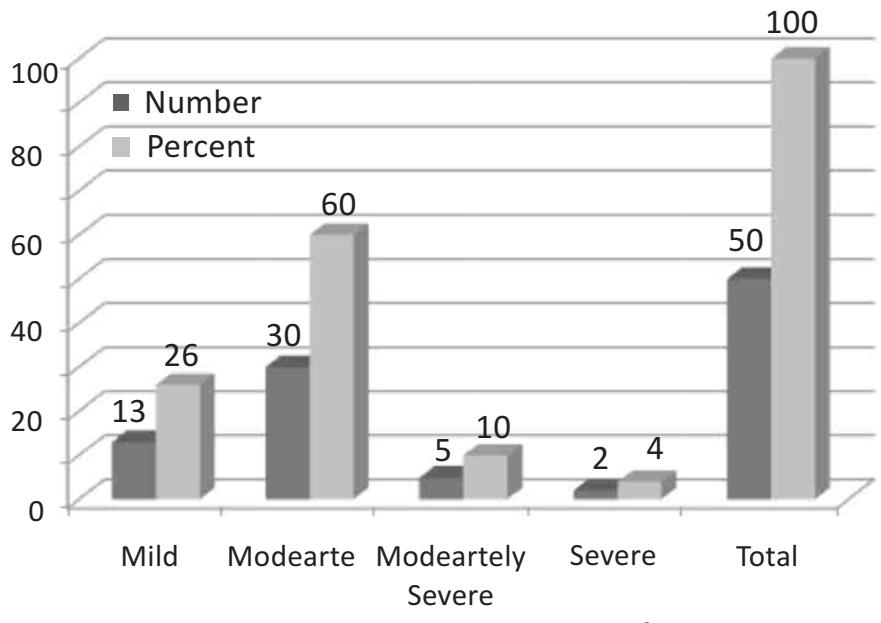

Figure 2: Preoperative Hearing loss 


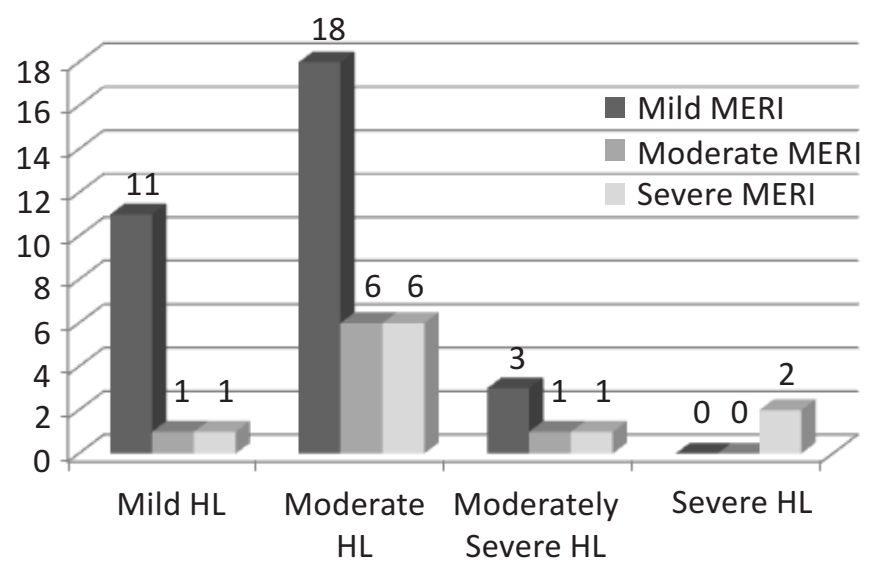

Figure 3: Correlation between MERI and preoperative hearing loss

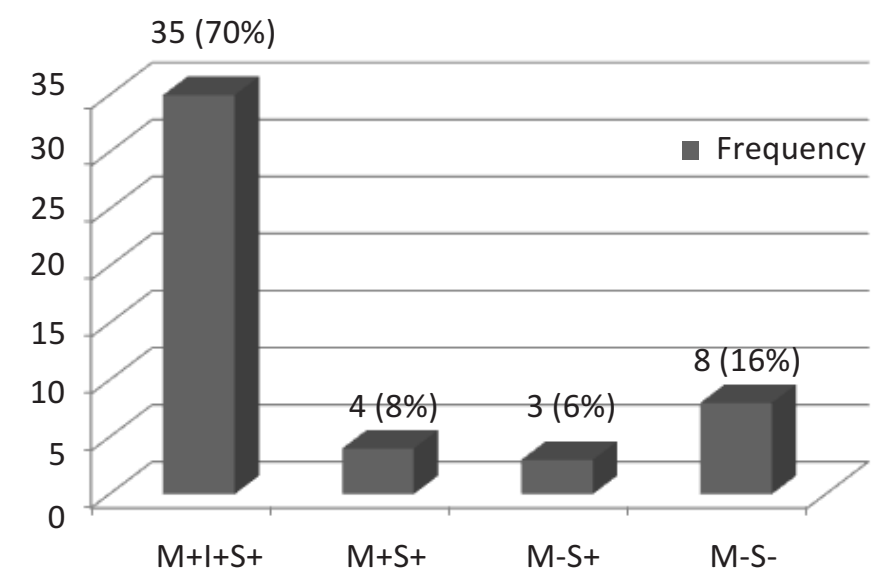

Figure 4: Ossicular status operatively

\begin{tabular}{|c|c|c|c|c|c|c|}
\hline \multirow[b]{2}{*}{ MERI } & \multicolumn{3}{|c|}{$1^{\text {st }}$ month PTA average categorization } & \multirow[b]{2}{*}{ Total } & \multirow[b]{2}{*}{$p$ value } & \multirow[b]{2}{*}{$\begin{array}{c}\text { Mean PTA } \\
\operatorname{avg}(\mathrm{dB})\end{array}$} \\
\hline & Mild HL & Moderate HL & $\begin{array}{c}\text { Moderately } \\
\text { Severe HL }\end{array}$ & & & \\
\hline Mild & 22 & 5 & 0 & 27 & \multirow{3}{*}{0.015} & $34.93 \pm 5.72$ \\
\hline Moderate & 4 & 2 & 0 & 6 & & $36.83 \pm 4.62$ \\
\hline Severe & 3 & 1 & 2 & 6 & & $44.67 \pm 13.85$ \\
\hline Total & 29 & 8 & 2 & 39 & & \\
\hline
\end{tabular}

Table IV: Correlation between MERI and first month PTA average:

\begin{tabular}{|c|c|c|c|c|c|c|}
\hline & \multicolumn{2}{|c|}{$\mathbf{2}^{\text {nd }}$ month PTA average categorization } & & Total & $\begin{array}{c}\text { Mean PTA value } \\
\text { avg(dB) }\end{array}$ \\
\hline $\begin{array}{c}\text { MERI } \\
\text { Score }\end{array}$ & Normal & Mild HL & Moderate HL & 21 & $28.95 \pm 4.2$ \\
\hline Mild & 5 & 16 & 0 & 6 & 0.004 \\
\cline { 1 - 5 } Moderate & 1 & 5 & 0 & 6 & $30.33 \pm 5.39$ \\
\hline Severe & 1 & 2 & 3 & 33 & \\
\hline Total & 7 & 23 & 3 & & \\
\hline
\end{tabular}

Table V: Correlation between MERI and second month PTA average

\begin{tabular}{|c|c|c|c|c|c|c|}
\hline & \multicolumn{2}{|c|}{$\mathbf{3}^{\text {rd }}$ month PTA average categorization } & & Total & $\begin{array}{c}\text { Mean PTA value } \\
\text { avg(dB) }\end{array}$ \\
\hline MERI & Normal & Mild HL & Moderate HL & 16 & $24.62 \pm 5.01$ \\
\hline Mild & 11 & 5 & 0 & 6 & $26.16 \pm 4.02$ \\
\hline Moderate & 2 & 4 & 0 & 6 & $38.17 \pm 8.99$ \\
\hline Severe & 1 & 3 & 2 & 28 & \\
\hline Total & 14 & 12 & 2 & & \\
\hline
\end{tabular}

Table VI: Correlation between MERI and third month PTA average 


\begin{tabular}{|l|c|c|}
\hline A-B gap & Mean \pm SD & p value \\
\hline Pre OP A-B gap & $37.36 \pm 5.73$ & \\
\hline First month A-B gap & $30.97 \pm 6.81$ & 0.0001 \\
\hline Second month A-B gap & $26.09 \pm 6.98$ & 0.0001 \\
\hline Third month A-B gap & $22.28 \pm 7.53$ & 0.0001 \\
\hline
\end{tabular}

Table VIII: Correlation between preoperative and postoperative A-B gap

\section{DISCUSSION}

Hearing result post tympanoplasty depends on a variety of well-identified factors related to both the pathologic condition and the surgical strategy and technique. In the past, studies described success in terms of hearing improvement only when elimination of infection and preservation or restoration of anatomy was present. Therefore, results today are reported in relation to control of pathology, anatomic status, hearing improvement, and postoperative complications. In the developing countries the cost of surgery and absence from the work are major restrains for two stage surgical procedure. If we can predict the outcome of the treatment depending upon different middle ear risk factors this will improve the patients compliance ${ }^{6}$.

The ideal tympanoplasty restores sound protection for the round window by constructing a closed air containing middle ear and rebuilds the sound pressure transformation mechanism for the oval window by connecting a large tympanic membrane with the stapes footplate via either an intact or a reconstructed ossicular chain ${ }^{2}$.

In this study the mean preoperative PTA average was $44.34 \mathrm{~dB}$ (SD $8.01 \mathrm{~dB}$ ) for patient with mild MERI, $44.75 \mathrm{~dB}$ (SD $5.87 \mathrm{~dB}$ ) for patient with moderate MERI and $54.9 \mathrm{~dB}$ (SD $14.05 \mathrm{~dB}$ ) for patient with severe MERI and the mean preoperative A-B gap was $37.36 \mathrm{~dB}$ (SD $5.73 \mathrm{~dB}$ ). In this study, third month PTA average was $24.62 \pm 5.01 \mathrm{~dB}$ for patient with mild MERI, $26.16 \pm 4.02 \mathrm{~dB}$ for patient with moderate MERI and 38.17 \pm 8.99 $\mathrm{dB}$ for patient with severe MERI which was statistically significant and the mean $A-B$ gap at first follow-up was $30.97 \pm 6.81 \mathrm{~dB}$, second follow-up was $26.09 \pm 6.98 \mathrm{~dB}$ and the third follow-up was $22.82 \pm 7.53 \mathrm{~dB}$ which was highly significant. Post operatively for mild MERI mean hearing gain is improved by $12-14 \mathrm{~dB}$, for moderate MERI mean hearing gain is improved by $10-13 \mathrm{~dB}$ and for severe MERI mean hearing gain is improved by $10-13 \mathrm{~dB}$ and post operative mean $\mathrm{A}-\mathrm{B}$ gap was improved by $10-11 \mathrm{~dB}$. There is a statistically significant hearing improvement in A-B gap with different groups of MERI.

Similar study was done by Chrobok V et al (2009) shows patients with lower MERI had significantly better pre-op and post-op air and bone conduction than patients with a higher MERI. In patients with a mild MERI hearing improved by 4 to 6 $\mathrm{dB}$. In patients with moderate and severe MERI hearing improvement was not seen ${ }^{7}$. The study done by Alshehabi $M$ 2010 the mean preoperative $A B G$ was $38 \mathrm{~dB}$, and the mean postoperative $A B G$ was $25.3 \mathrm{~dB}$ achieved ${ }^{8}$ were as Demir UL et al 2012 they found that the $A B G$ gain $(p=0.001$ and $p=0.014)$ and air-conduction improvement ( $p<0.001$ for both) were statistically significant in the mild- and moderate-risk groups, whereas those changes were found to be insignificant in the severe-risk group ${ }^{9}$.

In the present study it was found that the A-B gap and air conduction improvement is statistically significant for patients with mild, moderate and severe MERI.

\section{CONCLUSION}

This study shows that statistically significant prognostic difference was found in those patients who had higher middle ear risk index (MERI) as compared to patients with a mild MERI and moderate MERI. This concludes that the aggregate MERI is a good prognostic factor for hearing before and after surgery.

\section{REFERENCES}

1. Shenoi PM. Management of CSOM. In: Kerr AG, Booth JB, editors. Scott Brown's otolaryngology, $5^{\text {th }}$ ed. London, Butterworth and company; 1987;215-37.

2. Glasscock ME, Gulya AJ. Shamb Baugh GE. Surgery of the ear . Philadelphia WB Saunder.1959; 336-7.

3. Becvarovski Z, Kartush JM. Smoking and tympanoplasty: implications for prognosis and the Middle Ear Risk Index (MERI). Laryngoscope 2001;111:1806-11.

4. Black B. Design and development of a contoured ossicular replacement prosthesis: clinical trials of 125 cases. Am J Otol 1990;11:85-89.

5. Flint PW, Haughey BH, Lund VJ et al. Cumming's Otolaryngology Head and Neck Surgery, Philadelphia Mosby Elsevier 5th edition. 2010;1999-2000.

6. Kartush JM. Ossicular chain reconstruction: capitulum to malleus. Otolaryngol Clin North Am 1994;27:689-15.

7. Chrobok V, Pellant A, Meloun $M$ et al. Prognostic Factors for Hearing Preservation in Surgery of Chronic Otitis Media. Int. Adv. Otol. 2009; 5:(3) 310-317.

8. Alshehabi M. Middle Ear Risk Index : A Prognostic Factor in Pediatric Ossicular Reconstruction. Otolaryngology - Head and Neck Surgery 2010 143: 260.

9. Demir UL, Karaca S, Ozmen OA et al. Is it the middle ear disease or the reconstruction material that determines the functional outcome in ossicular chain reconstruction. Otol Neurotol. 2012 Jun;33(4):580-5. 